\title{
Mouse Cerebellar Granule Neurons Arrest the Proliferation of Human and Rodent Astrocytoma Cells in vitro
}

\author{
Mary E. Hatten and Michael L. Shelanski \\ Department of Pharmacology, New York University School of Medicine, New York, New York 10016
}

To understand the control of glial tumor cell proliferation, we have examined the effects of neurons on a number of human and rodent glioma lines. These included C6, G26-24, U-251, HTB-16, and A-172 cells of astroglial lineage and G26-20 of bipotential astrocytic and oligodendrocytic lineage. Rapid, specific binding of granule neurons to the human A-172, HTB-16, and U-251 and mouse G26-24 cell lines occurred, after which ${ }^{3} \mathrm{H}$-thymidine incorporation by these astrocytoma cells dropped 2-5-fold within $12 \mathrm{hr}$. The number of glial cells remained constant for 5-7 d when the glia were cocultured with granule neurons. Thereafter many neurons detached from the glial cells and glial proliferation commenced again. No effects on glial cell number were seen when PC12 cells were substituted for cerebellar granule neurons.

To test the mechanism of neuronal control of glioma cell growth, we added granule neurons or PC12 cells that had been fixed lightly with paraformaldehyde, a plasma membrane fraction of purified granule cells, PC12 cells or astrocytoma cells, or medium conditioned by either granule cells or a mixed population of cerebellar neurons and astroglia. The proliferation of responsive glioma cell lines ceased in the presence of either fixed granule neurons or plasma membranes purified from granule neurons. The addition of fixed PC12 cells or plasma membranes purified from PC12 cells, 3T3 cells, or astrocytoma cells had no effect on glial cell growth. Glioma cell growth was also unaffected by conditioned medium. Thus, neuronal control of astrocytoma cell proliferation appeared to be mediated by elements of the granule cell plasma membrane.

Neuronal regulation of astrocytoma cell growth depended on the ratio of the neurons to the glial cells rather than on the density of the glial cells. The optimal neuron : glia ratio was $4: 1$, where a 3-5-fold decrease in astrocytoma ${ }^{3} \mathrm{H}$-thymidine incorporation was seen. In contrast, the level of ${ }^{3} \mathrm{H}$ thymidine incorporation by G26-24 astrocytoma cells did not decrease when the cells were grown to very high density in the absence of neurons.

These studies suggest that there are 2 independent mechanisms that control glial cell growth-a heterologous (neuron-glial) mechanism and a homologous (glial-glial) mechanism.

\footnotetext{
Received May 29, 1987; revised Sept. 4, 1987; accepted Sept. 5, 1987.

We thank José Sanchez for his expert technical assistance and Drs. Carol Mason and Trevor Stitt for reading the manuscript. Peter Pierce prepared the photographic plates and Julia Cohen kindly typed the manuscript. This work was supported by NIH Grant 21097 to M.E.H.

Correspondence should be addressed to Mary E. Hatten, Ph.D., at her present address: Department of Pathology, College of Physicians and Surgeons, Columbia University, 630 West 168th Street, New York, NY 10032.

Copyright (C) 1988 Society for Neuroscience $0270-6474 / 88 / 041447-07 \$ 02.00 / 0$
}

Tumors of astrocytic lineage are the most common and devastating of the mammalian CNS. A variety of such tumors have been described in the neuropathological literature, ranging from slowly growing grade I astrocytomas, having cells with characteristic astrocytic morphology, to the very rapidly growing anaplastic astrocytomas and glioblastoma multiforma, characterized by cellular pleomorphism, necrosis, and endothelial proliferation (Russell and Rubenstein, 1977; Eng and Rubenstein, 1978; Bigner et al., 1981). Little is known about the origin of astroglial cell tumors. The possibility that one of the steps in the transformation of normal astrocytes into rapidly dividing tumor cells includes a loss of proper interactions with neurons has not been addressed.

Experiments on normal primary astrocytes taken from developing mouse cerebellum show that neurons can arrest astrocyte cell division (Hatten, 1985). The mechanism of the neuronal control of normal astroglial growth and differentiation appears to be mediated by elements of the plasma membrane and not by trophic factors, since fixed neurons or plasma membrancs isolated from ncurons, but not medium conditioned by neurons, inhibit glial growth (Hatten, 1987). In order to investigate whether neurons exert a similar control on tumor cells, we have exploited our ability to prepare large numbers of pure cerebellar granule cells from the early postnatal mouse and our microculture system.

In the present study, we have analyzed the influence of granule neurons on the growth of 7 different astrocytoma cell lines. The glioma cells we analyzed were all taken from permanent cell lines obtained originally from primary tumors of brain (Pfeiffer, 1977). Six different lines were studied, deriving from different species-human, rat, and mouse-and from different regions of the brain - cerebral cortex, cerebellum, and brain stem.

\section{Materials and Methods}

Purification of mouse cerebellar granule neurons. Whole cerebellum was removed from C57B1/6J mice on the second to fourth days postnatal, dissociated into a single-cell suspension, as described by Hatten and Francois (1981), and separated into enriched neuronal and glial fractions by a step gradient of Percoll. Further purification was achieved by preplating the neuronal fraction on a culture surface treated with polylysine $(50 \mu \mathrm{g} / \mathrm{ml})$ (Hatten, 1985). The purity of the granule neuron fraction, as judged by immunostaining with 2 cellular antigen markers, antisera against the glial filament protein (AbGFP) to identify astroglia and the nerve growth factor-inducible large external glycoprotein (AbNILE) to identify neurons (Hatten et al., 1984), was greater than $99 \%$ neuronal.

Granule neurons were prepared just prior to plating the glioma cells and were then used immediately.

Glioma cell lines. Human U-251 astrocytoma cells (Westermark, 1973) were the generous gift of Dr. R. K. H. Liem of this Department; HTB16 and A-172 cells were the gift of Dr. R. Della Favarra of the Department of Pathology and Dr. Darrel Bigner of Duke University School 
of Medicine. G26-24 and G26-20 mouse glioma cells (Sundarraj et al., 1975) and C6 rat glioma cells (Benda et al., 1971) were the gift of Dr. S. Pfeiffer of the University of Connecticut. All glioma cell lines were maintained in Eagle's Basal Medium supplemented with $10 \%$ horse (Gibco) or 10\% fetal bovine serum (Gibco).

Binding of neurons or neuronal membranes to glioma cells. To measure the kinetics of binding of granule neurons to a series of glioma cell lines, purified granule neurons or an enriched plasma membrane fraction obtained from the cell preparation (Hatten, 1987) was added to glioma cells grown to confluency. The ratio of neurons to glioma cells varied between $1: 1$ and 10:1. After $1-48 \mathrm{hr}$, the cell culture dish was shaken vigorously, unbound neurons were removed by washing, and the percentage of bound neurons was calculated. This figure was confirmed by counting the number of bound cells by microscopy and, in some experiments, by first loading the neurons with the fluorescent dye carboxymethyl fluorescein diacetate (CFDA) and then adding them to glioma cell cultures (Hatten, 1987). In other experiments, we used the method of Colc and Glascr (1984) to radiolabcl ncurons with ${ }^{35} \mathrm{~S}-\mathrm{mcthioninc}$ $(100 \mu \mathrm{Ci} / \mathrm{ml})$ for $3-4 \mathrm{hr}$ prior to adding them to the glioma cells and then measured neuronal binding by removing the cells at various time points, precipitating the total protein with trichloroacetic acid, and counting the amount of ${ }^{35} \mathrm{~S}$-methionine bound.

${ }^{3} \mathrm{H}$-Thymidine incorporation assays. The influence of neurons on glial thymidine incorporation was measured as described by Hatten (1987).

Fixation of granule cells for binding assays. Freshly prepared granule cells or PC12 cells (Greene and Tischler, 1976) were fixed with 0.01$4.0 \%$ paraformaldehyde for $30 \mathrm{~min}$ at room temperature, washed 3 times with PBS, and used for binding assays or for coculture experiments.

Preparation of conditioned medium. Spent medium was collected after 1-3 d of culture from either mixed cultures of cerebellar cells harvested from P7 animals, cultures of purified granule neurons, or purified astroglial cells (Hatten, 1987). In some cases, the medium was concentrated up to 50 -fold by vacuum dialysis.

Coculture of granule neurons and astrocytoma cells in separate chambers with intermixed culture medium. Four different culture vessels were used to test the influence of confluent neuronal culture medium on astroglial cells cultured in a separate chamber. The details of these cultures are presented elsewhere (Hatten, 1987).

Preparation of an enriched plasma membrane fraction from purified granule neurons. Plasma membranes were prepared from freshly purified mouse granule neurons by the method of Brunette and Till (1971) as described by Hatten (1987). The final concentration of granule cell membrane protein material in the culture medium was $0.4-6.0 \mu \mathrm{g} / \mathrm{ml}$.

Combined immunocytochemical localization of glial flament protein and autoradiographic localization of ${ }^{3} \mathrm{H}$-thymidine. For autoradiography, cells were labeled with $100 \mu \mathrm{Ci} / \mathrm{ml}$ of $\mathrm{G}^{3} \mathrm{H}$-thymidine $(5 \mathrm{Ci} / \mathrm{mmol}$; Amersham International, UK) for 3-4 hr, washed, fixed immediately with paraformaldehyde (4\%), and stained with antisera against the glial filament protein by the peroxidase-antiperoxidase method, as described previously (Hatten et al., 1984). After air-drying, the slides were rinsed with water, dipped in fresh Ilford L-4 emulsion, exposed for 2-3 d, and developed with $\mathrm{D}-19$ developer.

\section{Results}

Mouse cerebellar granule neurons attached rapidly to 4 of the 6 astrocytoma cell lines tested - the human A-172, HTB-16, and U-251 lines and the mouse G26-24 line. Granule cells did not attach to rat C6 or mouse G26-20 cells. As can be seen in Figure 1, binding was complete in approximately $30-40 \mathrm{~min}$. This neuronal binding to glioma cells was not dependent on calcium and was not reversed by agitation of the cells in calciumand magnesium-free buffer containing $0.2 \mathrm{mg} / \mathrm{ml}$ of EDTA, suggesting that it did not derive from nonspecific ionic interactions.

The interactions of granule neurons with glioma cells closely resembled their interactions with primary, early postnatal mouse cerebellar astroglia (Hatten, 1985). By light microscopy, in some cases after immunostaining with cellular antigen markers, the neurons were found to have formed numerous cell-cell contacts with the glioma cells (Fig. 2,b, d). The most striking results of coculturing the astrocytoma cells with granule neurons was the

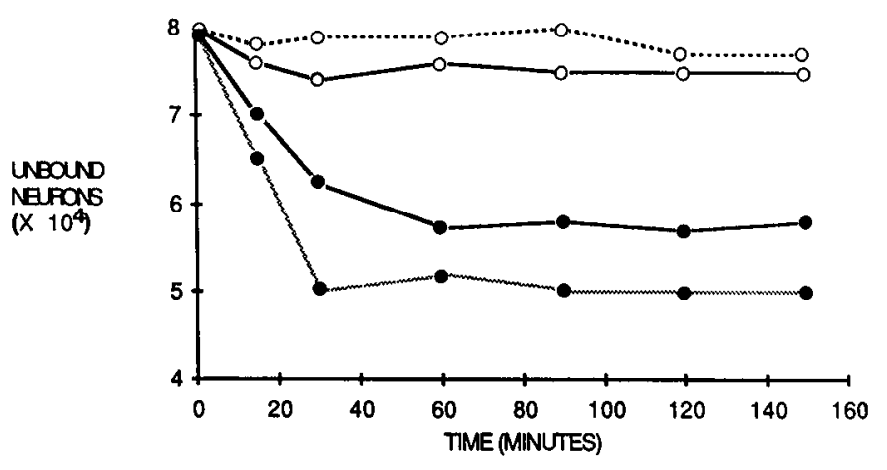

Figure 1. Kinetics of binding of granule neurons to astrocytoma cells. Purified granule neurons were added to a confluent monolayer of human HTB-16 (solid lines) or mouse G26-24 (dashed lines) astrocytoma cells. After $0,15,30,60,90,120$, or $150 \mathrm{~min}$, the culture dish was shaken vigorously on a platform shaker, the medium was removed, and the number of unbound neurons was counted with a Coulter counter (closed circles). As a control, duplicate samples of neurons were added to empty culture dishes (open circles).

reduction in the number of glioma cells. Five days after plating equal numbers of glioma cells in culture, 4-5 times as many glioma cells were seen in the absence of neurons (Fig. 2, $a, c$ ) as were seen when glioma cells were cocultured with granule cells (Fig. 2, $b, d$ ).

The effects of neuron binding on glial cell proliferation were not species-specific. The mouse granule neuron regulated the division rate of rodent and human cells with similar efficacy. When granule cells from postnatal day 2 were added to the A-172, G-26-24, HTB-16, and U-251 cell lines, lines to which binding had been observed, proliferation stopped within a 20 hr period. Results of experiments with the HTB-16, U-251, and G26-24 cell lines are shown in Figure 3. Identical results were seen with the A-172 cell line. Granule cells did not alter the growth rate of $\mathrm{C} 6$ or $\mathrm{G} 26-20$ glioma cells.

When neurons were removed from responsive glioma cells by vigorously shaking the culture dish, the resumption of glial cell division followed the release of bound neurons, suggesting that neuronal control of astrocytoma proliferation is reversible and that it depends on neuron-glial contacts.

To analyze more precisely the time course of the effects of neurons on glial proliferation, we measured the incorporation of ${ }^{3} \mathrm{H}$-thymidine by the glial cells over the first $24 \mathrm{hr}$ after neuronal addition. These studies showed that ${ }^{3} \mathrm{H}$-thymidine incorporation dropped 2-5-fold within $12 \mathrm{hr}$ of adding the neurons (Fig. 4). The effect of neurons on astroglial cells depended on the number of neurons that we added and on the time at which we added them. For proliferation to cease, a cell-cell ratio of at least 4 neurons per glial cell was required. The addition of more than 4 neurons per glioma cell did not result in any further inhibition of thymidine incorporation. In addition, glial growth inhibition was maximal when neurons were added at the time the glial cells were plated. If neurons were added after the glial cells had begun to grow in culture, a subpopulation of cells escaped inhibition. Complete responsiveness could be restored by synchronizing the glioma cells by starvation in medium depleted of one or more of the following: isoleucine, methionine, or serum.

To assess whether all of the glial cells or a subset responded to the neurons, we added the neurons, left them in coculture for 3-5 d, labeled the cells with ${ }^{3} \mathrm{H}$-thymidine for $3 \mathrm{hr}$, washed and 

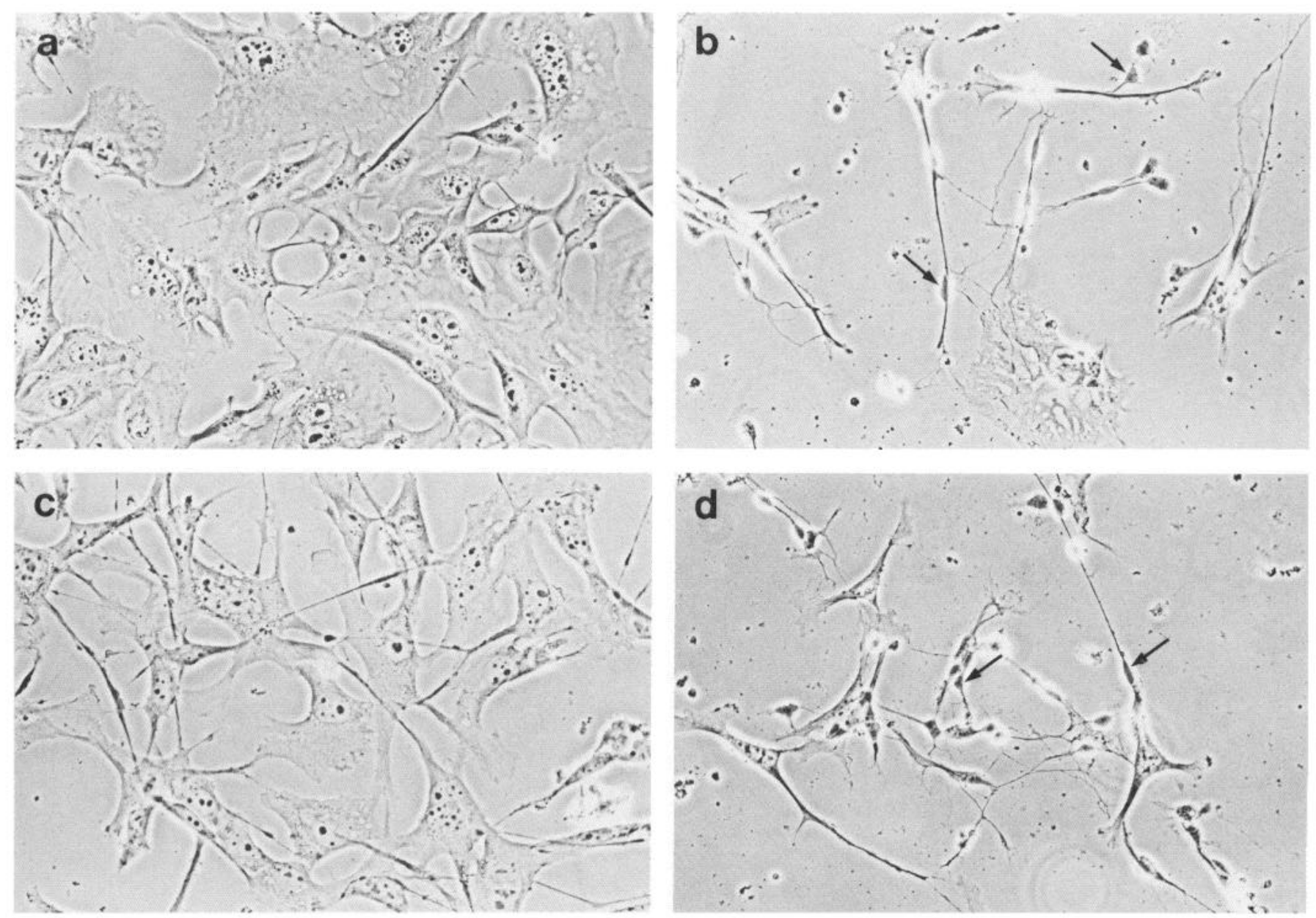

Figure 2. Effect of granule neurons on the growth and morphology of human HTB-16 and mouse G26-24 astrocytoma cells. Purified granule neurons were added at a ratio of 4 neurons per glial cell at the time the glioma cells were plated. After $5 \mathrm{~d}$ in vitro, the culture was fixed with paraformaldehyde (4\%) and photographed by phase-contrast light microscopy. Control cultures of $(a)$ HTB-16 and (c) G26-24 glioma cells grown in the absence of neurons illustrate the rapid growth of astrocytoma cells. HTB-16 $(b)$ and G26-24 (d) cells were cocultured with granule neurons at a cell : cell ratio of 4 neurons per glial cell. Neurons bind to the glial cells, the growth of the glial cells is inhibited, and some of the glial cells have elongated processes. Arrows illustrate granule neurons bound to astrocytoma cell processes. Phase-contrast microscopy. $\times 150$.

fixed the cells, and counted the number of darkly or lightly labeled glial cells (Figs. 5, 6). These experiments showed that neurons inhibited the thymidine incorporation of more than $90 \%$ of the astrocytoma cells in the culture.

We analyzed the mechanism of neuronal control of glioma cell proliferation by carrying out a series of experiments with medium conditioned by neurons or by mixed cultures of neurons and astroglia, either with concentrated conditioned medium or by coculturing the glioma cells with neurons in culture devices that allowed the medium, but not the cells, to intermix (Hatten, 1987). No effects on glial growth were seen with conditioned media or when the cells were cultured with intermixed media.

In contrast to the results with conditioned media, granule cells that were lightly fixed with paraformaldehyde attached to and arrested the growth of all of the glioma cells that were responsive (A-172, G26-24, HTB-16, and U-251) to living granule neurons (Fig. 7). As was seen for normal, cerebellar astroglial cells, the binding of fixed cells to astrocytoma cells depended on the amount of paraformaldehyde used to fix the neurons. Very dilute concentrations of fixative $-0.1-0.5 \%-$ had to be used. At a higher concentration of paraformaldehyde, the cells did not bind to the glia and growth inhibition was not seen. At concentrations of paraformaldehyde that still allowed neuronal adhesion to the astrocytoma cells, glial cell DNA synthesis of A-172, HTB-16, U-251, and G26-24 cells diminished 2-5-fold within 6-12 hr and glial growth ceased (Fig. 7).

As a control, to demonstrate that formaldehyde-fixed neurons were not toxic to astrocytoma cells, we added fixed $\mathrm{PC} 12$ cells to cultures of A-172, HTB-16, and G26-24 glioma cells. When fixed with $0.1-4.0 \%$ paraformaldehyde, $\mathrm{PC} 12$ cells did not influence the growth rate of any of these astrocytoma cell lines.

Cell-surface membranes purified from granule neurons bound to all but the C6 and G26-20 cell lines at a rate that paralleled the binding of intact neurons to glioma cells. As was seen with both living and lightly fixed granule cells, neuronal membrane binding was followed by a rapid decline in thymidine incorporation and a cessation of cell division (Figs. 6, 8). For all of the responsive lines (A-172, HTB-16, U-251, and G26-24), the effect of the membranes was dose-dependent. Glial growth was arrested when the final concentration of added granule cell membrane protein material was $2-6 \mu \mathrm{g} / \mathrm{ml}$. Lower doses of granule cell membranes did not inhibit glial cell growth.

In contrast to the results with cerebellar granule neurons, 


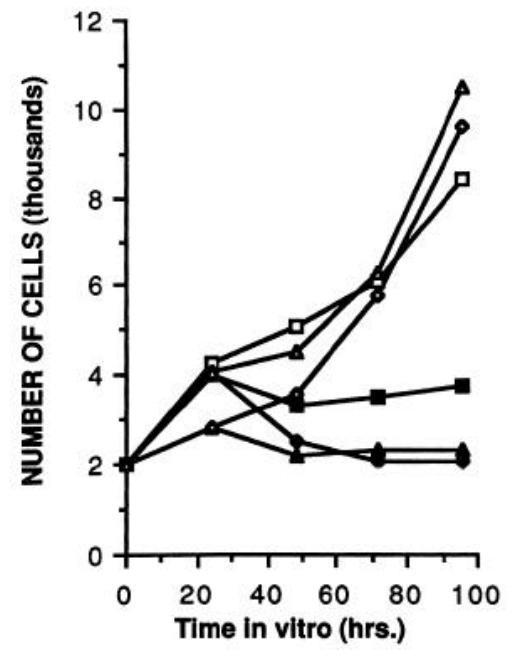

Figure 3. Effect of granule neurons on human and mouse astrocytoma cell growth rates. Granule neurons were purified from early postnatal mouse cerebellar cortex as described (Hatten, 1985), were added to freshly plated human HTB-16 $(\triangle)$, human U-251 $(\square)$, and mouse G26$24(\diamond)$ astrocytoma cells at plating. After $24,48,72$, or $96 \mathrm{hr}$, the cultures were fixed with paraformaldehyde (4\%), stained with AbGFP as described (Hatten et al., 1984), and immunopositive glial cells were counted by microscopy. Astrocytoma cell proliferation is rapid in the absence of neurons (open symbols). In contrast, when cocultured with granule cells, astrocytoma cell growth is inhibited (closed symbols).

PC12 neurons, a cell line obtained originally from a pheochromocytoma that has been shown to express neuronal characteristics when cultured in the presence of the nerve growth factor, did not bind to any of the glioma cell lines tested and did not influence their growth rates. Furthermore, fixed PC12 cells and PC12 membranes neither bound to nor regulated the growth of any of the astrocytoma cell lines we studied (Table 1). These results are consistent with our earlier finding that PC12 cells failed to bind to cerebellar astroglial cells in microcultures (Hatten and Liem, 1981).

To compare the effects of neurons on glial growth with those of glial-glial cell contacts, we cultured G26-24 astrocytoma cells

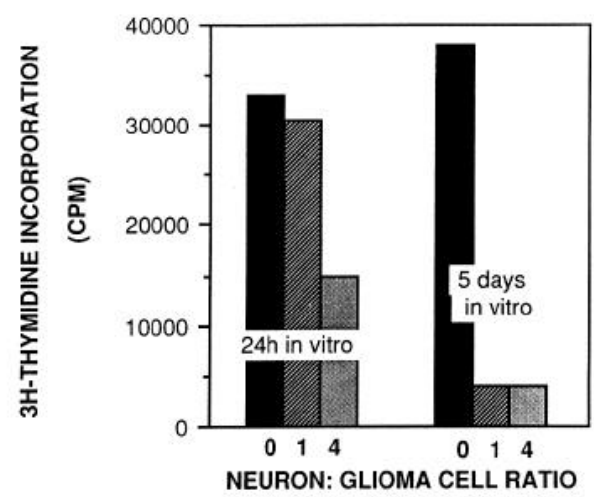

Figure 4. Effect of granule neurons on DNA synthesis of astrocytoma cells. To quantitate the effects of neurons on DNA synthesis, mouse G26-24 glioma cells were incubated with granule neurons at a cell: cell ratio of $1-4$ neurons per glial cell for $1-24 \mathrm{hr}$, after which they were labeled with ${ }^{3} \mathrm{H}$-thymidine for $3 \mathrm{hr}$, washed, removed from the dish with a rubber policeman, precipitated with trichloroacetic acid, and counted for thymidine incorporation. The number of glial cells plated in duplicate wells was within $5 \%$. The results shown are averaged values from 5 duplicate wells; the standard deviation was less than $6 \%$.
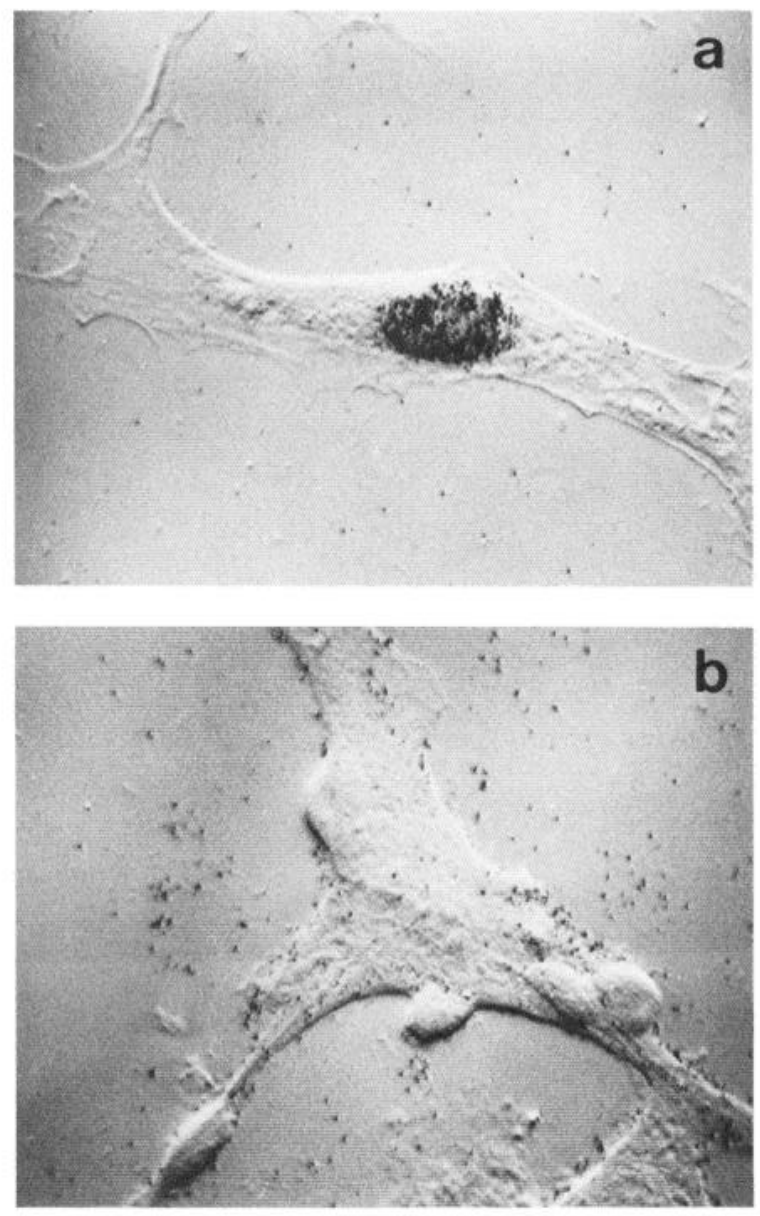

Figure 5. Autoradiography of astrocytoma cells grown in the presence or absence of neurons. After $3 \mathrm{~d}$ in vitro, human HTB-16 astrocytoma cells were incubated for $3 \mathrm{hr}$ with ${ }^{3} \mathrm{H}$-thymidine, washed, fixed with paraformaldehyde, and processed for autoradiography. In $a$, an HTB16 cell cultured without neurons is heavily labeled, whereas in $b$, HTB16 cells cultured in the presence of granule neurons are unlabeled. The astrocytoma cell in $b$ is seen in the center of a cluster of small $(5-8 \mu \mathrm{m})$ neurons. Nomarski optics, enhanced by a Hamamatsu C-1965 Chalnicon camera. Photographs were taken from the video monitor as described in Edmondson and Hatten (1987). ×570.

in the absence of neurons, allowed the cells to grow to different levels of confluency, and measured their rate of thymidine incorporation (Fig. 9). We used primary astroglial cells harvested from early postnatal mouse cerebellum as a control for these experiments, because they grow progressively more slowly as they reach high density (our unpublished observation) and because granule neurons can regulate the growth of cerebellar astroglia (Hatten, 1985, 1987). Whereas normal astroglial cells incorporated about a third less ${ }^{3} \mathrm{H}$-thymidine at confluency than when they were subconfluent, G26-24 cells continued to incorporate high levels of ${ }^{3} \mathrm{H}$-thymidine even after they reached confluency. On a per cell basis, G26-24 cells at confluency incorporated 3-4-fold more thymidine than did normal cells.

As a control for the experiments with the granule neuron membrane material, we added membranes purified from $\mathrm{Balb} / \mathrm{c}$ $3 \mathrm{~T} 3$ cells and from the astrocytoma cells whose growth we had measured. Although all of these fractions bound to the astrocytoma cells, none influenced the growth rate of the cell lines we studied, suggesting that the effect of the granule cell membrane was "specific," i.e., related to an effect of the binding 


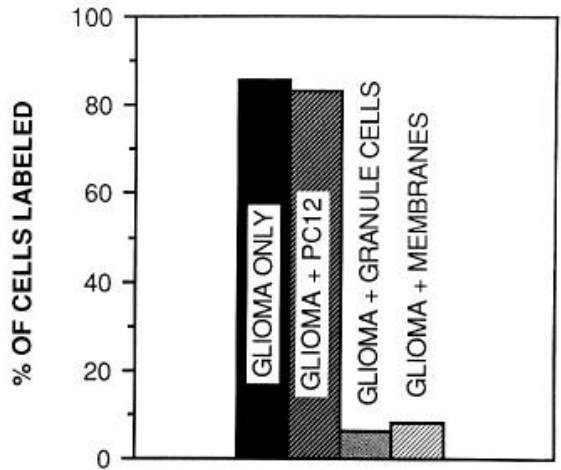

Figure 6. Effect of granule neurons, granule neuron membranes, or PC12 cell membranes on astrocytoma cell DNA synthesis. Mouse G2624 cells were cultured in the absence or presence of granule neurons, or of either granule neuron membranes or PC12 cell membranes. Granule neurons were added at a ratio of 4 neurons per glial cell. Equivalent amounts of membrane protein were added for granule neuron and $\mathrm{PC} 12$ cells; in each case, the final concentration of membrane protein added was $2 \mu \mathrm{g} / \mathrm{ml}$. After $5 \mathrm{~d}$ in vitro, the cultures were incubated with ${ }^{3} \mathrm{H}$ thymidine $(10 \mu \mathrm{Ci} / \mathrm{ml})$ for $3 \mathrm{hr}$, after which they were washed, fixed, immunostained with antibodies against the glial filament protein, and processed for autoradiography. The number of heavily labeled (see Fig. 7), immunopositive astrocytoma cells was counted by microscopy; 50 fields were counted at $400 \times$ magnification, and the number of heavily labeled astroglia was calculated as a percentage of the total number of stained cells counted. In the absence of granule neurons and when PC12 cell membranes were added to the astrocytoma cells, nearly all of the glial cells were heavily labeled. In contrast, when living granule neurons or a granule cell membrane fraction was added, fewer than $10 \%$ of the glia were heavily labeled.

of a ligand to a growth factor receptor or to the blockade of a post-receptor event involved in growth regulation.

\section{Discussion}

Earlier studies showed that proliferation of primary mouse cerebellar astrocytes in culture could be inhibited by granule neurons or their membranes (Hatten, 1985, 1987). Cell- and membrane-mediated regulation of cell division has been reported for

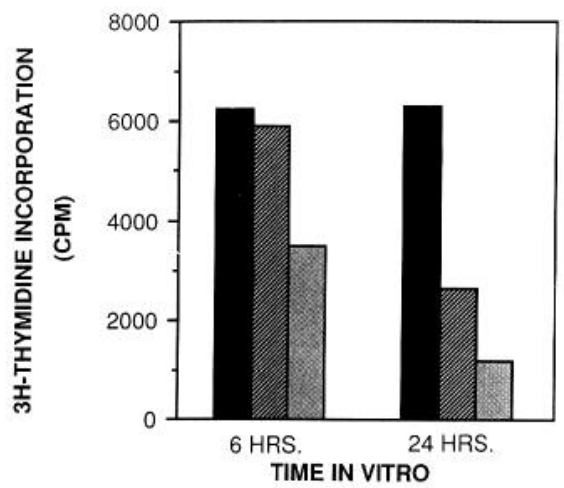

Figure 7. Effect of fixed granule neurons on astrocytoma cell DNA synthesis. Human U-251 cells were cultured in the absence (solid bars) or presence of granule neurons that had been fixed with either $1.0 \%$ (lined bar) or $0.5 \%$ (stippled bar) paraformaldehyde, washed, and added to the glia at a ratio of 4 neurons per glial cell. Six or $24 \mathrm{hr}$ after the addition of the fixed neurons, the cultures were radiolabeled with ${ }^{3} \mathrm{H}$ thymidine for $3 \mathrm{hr}$, washed, precipitated in trichloroacetic acid, and counted. Counts are per culture $\left(1 \mathrm{~cm}^{2}\right)$; the number of glial cells in duplicate cultures was within $5 \%$. Values given are averaged from counts of 7 duplicate cultures; the standard deviation among duplicate wells was less than $8 \%$.
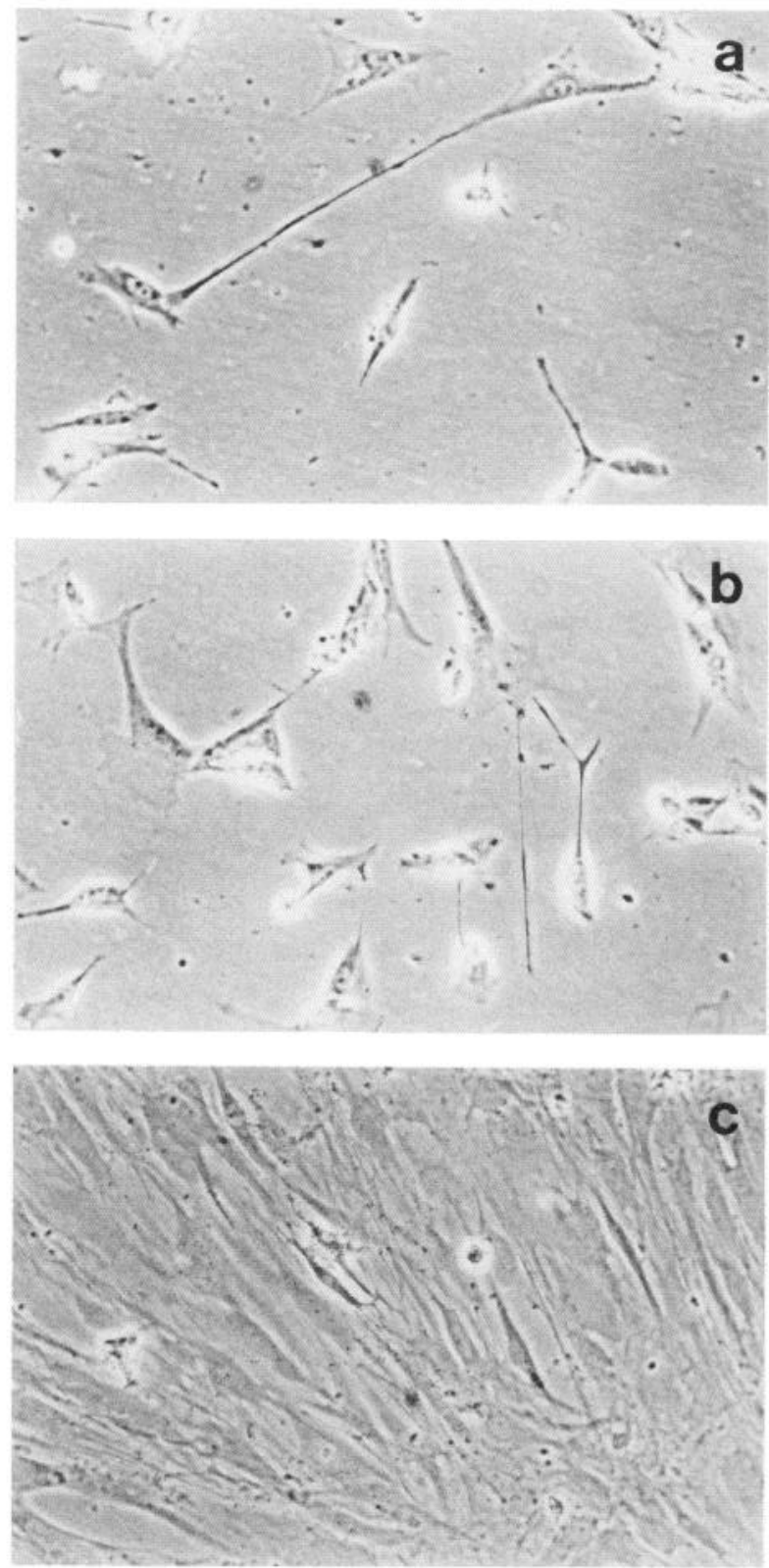

Figure 8. Effect of membranes purified from granule neurons on glial cell growth. Granule cell membrane material was added to the culture medium at a final protein concentration of $4 \mu \mathrm{g} / \mathrm{ml}$ at the time the $\mathrm{G} 26$ 24 glioma cells were plated. Phase-contrast microscopy after $5 \mathrm{~d}$ in vitro reveals an arrested proliferation of mouse G26-24 astrocytoma cells in the presence of neuronal membranes $(a, b)$, as compared with that of controls grown alone $(c)$. In $a$, an elongated astrocytoma form is seen in the center of the field. $\times 125$.

a variety of cell types (Todaro and Green, 1963). Membranes and membrane extracts from 3T3 cells inhibit DNA synthesis in 3T3 cell cultures (Whittenberger and Glaser, 1977; Whittenberger et al., 1978), and membrane-mediated interactions regulate cell growth in endothelial cells (Heimark and Schwartz, 1985). What sets the astrocyte apart is that the growth regulation is by a heterologous cell and that it depends on the ratio of the neurons to the astrocytes rather than the density of astrocytes in the culture dish.

Astrocytes cultured in the absence of neurons often display a cell density-dependent growth regulation. Primary astrocytes 


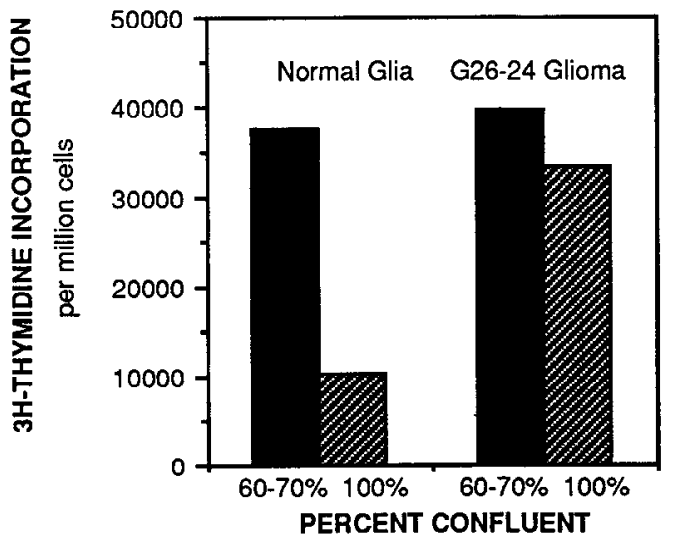

Figure 9. ${ }^{3} \mathrm{H}$-Thymidine incorporation of untransformed cerebellar astroglia and G26-24 glioma cells grown to confluency. Mouse cerebellar astroglia were purified as described (Hatten, 1985) and grown to either $60-70 \%$ or $100 \%$ confluency; mouse G26-24 glioma were plated as described and also grown to $60-70 \%$ or $100 \%$ confluency. At either point, the cells were incubated with ${ }^{3} \mathrm{H}$-thymidine for $3 \mathrm{hr}$, after which they were washed and counted for thymidine incorporation.

harvested from early postnatal mouse cerebellum (Hatten, 1985) or from rat cerebral cortex (McCarthy and DeVellis, 1980) grow progressively more slowly as their density increases (our unpublished observations; K. D. McCarthy, personal communication). The present results show that, whereas primary cerebellar astroglial cells show a marked decrease in DNA synthesis at confluency, mouse G26-24 glioma cells continue to incorporatc very high levels of ${ }^{3} \mathrm{H}$-thymidine even after they have formed a monolayer. Thus homologous (glial-glial) regulation of astrocyte growth is distinguished from heterologous (neuronglial) regulation by density-dependence.

All of the cell lines that bound the granule cells showed a rapid decrease in proliferation upon the addition of neurons or neuronal membranes. Neuronal inhibition of astrocytoma cell growth was optimal at a neuron : glioma cell ratio of $4: 1$ and occurred when the glioma cells were at very low cell density. The 2 cases in which inhibition did not occur (C6 and G26-20) were ones in which the glioma cell also lacked the ability to bind the neuron.

An important aspect of these experiments was that neuronal regulation of glioma growth occurred for cell lines with very different growth characteristics, levels of tumorigenicity when injected into nude mice, and levels of receptors for growth factors. Granule cells arrested both the growth of glioma cells that grow to very high cell densities (G26-24, A-172) and of those that grow more slowly as they reach confluency (U-251). Thus, although homologous (glial-glial) regulation was lost in some of the tumor lines we tested, heterologous (neuron-glial) regulation was conserved. Neuronal inhibition of the growth of A-172 cells was of special interest because this human cell line is one of the most tumorigenic glioma lines (Bigner et al., 1981), producing tumors in approximately $10 \%$ of injected animals, and because it expresses comparatively low levels of the EGF receptor (Westermark et al., 1985).

Neuronal inhibition of astrocytoma cell growth did not appear to be caused by a soluble factor. Instead, intact neurons, fixed neurons, neuronal membranes, and fixed neuronal membranes were all effective in diminishing glioma cell proliferation. These results suggest that neuronal regulation of astrocytoma growth, when it occurs, is membrane-mediated. This mechanism is con-
Table 1. Specificity of astrocytoma growth inhibition by plasma membrane fractions

\begin{tabular}{ll} 
Cellular source of membranes & $\begin{array}{l}\text { Inhibition of } \\
\text { astrocytoma } \\
\text { proliferation }\end{array}$ \\
\hline Cerebellar granule neurons & + \\
Cerebellar astroglia & - \\
PC12 neurons & - \\
Balb/c 3T3 fibroblasts & - \\
PTK2 epithelial cells & -
\end{tabular}

Membranes were purified by the method of Brunette and Till (1971) and added to A-172, G26-24, HTB-16, or U-251 glioma cells at plating. The number of glioma cells was measured by removing the cells with trypsin and counting them with a Coulter counter or a hemocytometer. A plus sign indicates a difference of more than $30 \%$ between cells grown in the presence and absence of membranes.

sistent with studies by Glaser and his colleagues, who showed that protein material purified from $3 \mathrm{~T} 3$ cell membranes would inhibit 3T3 cell growth (Whitten berger and Glaser, 1977; Whittenberger et al., 1978). What is novel about these experiments is that growth inhibition was seen for a heterologous cell membrane preparation, that of the granule neuron.

Two general mechanisms seem likely for granule cell-mediated inhibition of astrocytoma cell growth. First, the neuron could bind to a receptor for a growth factor and thereby block the mitogenic effect of the factor. Astrocytes in vitro release a number of growth factors into the culture medium, including platelet-derived growth factor (PDGF) (Nister et al., 1984), EGF (Westermark et al., 1985), fibroblast-derived growth factor (bFGF) (Hatten et al., 1988), and insulin-like factors (King and Kahn, 1985), and respond to a number of mitogens purified from whole brain, including the glial growth factor (Brockes et al., 1980). Thus it is possible that the granule cell membrane material blocked growth factor binding or postreceptor events needed for glial cell division.

The fact that PC12 cell, 3T3 cell astrocyte, and astrocytoma cell membranes did not regulate glial growth argues against a general masking of growth factor receptors by the granule cell and for a more specific effect of the CNS granule neurons on astroglial growth. In this second model, the neuron would bind to a receptor needed for neuron-glial interactions, such as that for astrotactin, a novel neuronal antigen that mediates the formation of granule cell-astroglial contacts in microcultures (Edmondson et al., 1987). The astroglial receptor for astrotactin or other cell-cell contact ligands could either function as a growth regulator or influence postreceptor events such as cellular oncogene transcription. This model is supported by the finding that neuronal binding to the astrocytoma cells was needed for glial growth to cease.

The results of these studies point to the existence of at least 2 independent mechanisms that control proliferation in CNS astrocytes. It would appear that the heterologous (neuron-glial) mechanism remains intact in many tumors of the astrocytic series, while the homologous mechanism is defective. This defect could either be direct-involving, for example, a receptor that regulates growth-or it is possible that other alterations in the tumor cell override the normal control mechanisms. For example, alterations in the sis gene, which encodes a PDGFlike activity, and in the $e r b-B$ gene, which is homologous with the EGF receptor, have been implicated in human malignant gliomas (Westermark et al., 1985). However, if these growth 
factor-related oncogenes can override the "homologous mechanism," they appear unable to dominate the heterologous mechanism in the cell lines we have studied.

These results also suggest a model for the genesis and growth of glial tumors, in which the 2 mechanisms could operate singly or together. In the first case, an initial transforming event, perhaps in the "glial regulation," would cause the astrocytes to divide. However, as long as these astrocytes were in contact with neurons, growth would be slow. At the point at which there were cells that had only astrocytes as their nearest neighbors, growth would become much more rapid. Freed of neuronal control, possibly stimulated by growth factor-related oncogene products, these astrocytes would then proliferate rapidly, leading to tumor formation. It is also possible to envision a second group of tumors that lacked the neuron-dependent mechanism. These tumors would still have the weaker glial-glial control mechanism and might be expected to grow very slowly. The grade I astrocytomas might be such a case. A third category, lacking both control mechanisms, might produce the most malignant tumors, including the glioblastomas.

The finding that mouse granule cells bind to and regulate the growth of human, rat, or mouse astrocytoma cells obtained originally from different brain regions suggests that the mechanism for their interaction and for neuronal regulation of astrocyte growth is highly conserved. The relationship between oncogene products and cell-recognition molecules in astrocytic tumors, the existence of an apparent hierarchy of controls that we postulate, and the utility of this knowledge in devising therapeutic approaches all require further investigation.

\section{References}

Benda, P., K. Smeda, J. Messer, and W. H. Sweet (1971) Morphological and immunological studies of rat glial tumors and clonal strains propagated in culture. J. Neurosurg. 34: 310-323.

Bigner, D. D., D. M. Bullard, and C. N. Pegram (1981) Relationship of in vitro morphologic and growth characteristics of established human-derived cell lines to their tumorigenicity in athymic nude mice. J. Neuropathol. Exp. Neurol. 40: 390-409.

Brockes, J. P., G. E. Lemke, and D. R. Balzer, Jr. (1980) Purification and preliminary characterization of a glial growth factor from the bovine pituitary. J. Cell Biol. 255: 8374-8377.

Brunette, D. M., and J. E. Till (1971) A rapid method of isolation of L-cell surface membranes using an aqueous two-phase polymer system. J. Membrane Biol. 5: 215-224.

Cole, G. J., and L. Glaser (1984) Inhibition of embryonic neural retina cell-substratum adhesion with a monoclonal antibody. J. Biol. Chem. 259: 4031-4034.

Edmondson, J. C., and M. E. Hatten (1987) Glial-guided granule neuron migration in vitro: A high-resolution, time-lapse video microscopic study. J. Neurosci. 7: 1928-1934.

Edmondson, J. E., R. K. H. Liem, J. E. Kuster, and M. E. Hlatten (1987) Astrotactin, a novel surface antigen that mediates neuronglia contacts in microcultures. J. Cell Biol. 106: 505-517.
Eng, L. F., and L. J. Rubenstein (1978) Contribution of immunocytochemistry to diagnostic problems of human cerebral tumors. J. Histochem. Cytochem. 26: 513-522.

Greene, L. A., and A. S. Tischler (1976) Establishment of a noradrenergic clonal line of rat pheochromocytoma cells which respond to nerve growth factor. Proc. Natl. Acad. Sci. USA 73: 2424-2428.

Hatten, M. E. (1985) Neuronal regulation of astroglial morphology and proliferation in vitro. J. Cell Biol. 100: 384-396.

Hatten, M. E. (1987) Neuronal inhibition of astroglial cell proliferation is membrane-mediated. I. Cell Biol. 104: 1353-1360.

Hatten, M. E., and A. M. Francois (1981) Cell assembly patterns of developing cerebellar cells on lectin-derivatized culture substrata. Dev. Biol. 87: 102-113.

Hatten, M. E., and R. K. H. Liem (1981) Astroglial cells provide a template for the positioning of developing cerebellar neurons in vitro. J. Cell Biol. 90: 622-630.

Hatten, M. E., R. K. H. Liem, and C. A. Mason (1984) Two forms of cerebellar glial cells interact differently with neurons in vitro. J. Cell Biol. 98: 193-204.

Hatten, M. E., M. Lynch, R. E. Rydel, J. Sanchez, J. Joseph-Silverstein, D. Moscatelli, and D. B. Rifkin (1988) In vitro neurite extension by granule neurons is dependent upon astroglial-derived fibroblast growth factor. Dev. Biol. 125: 280-289.

Heimark, R. L., and S. M. Schwartz (1985) The role of membranemembrane interactions in the regulation of endothelial cell growth. J. Cell Biol. 100: 1934-1940.

King, G. L., and C. R. Kahn (1985) Effect of insulin on growth in vivo and cells in culture. In Control of Animal Cell Proliferation, vol. 1, A. L. Boynton and H. L. Leffert, eds., pp. 91-120, Academic, Orlando, FL.

McCarthy, K. D., and J. DeVellis (1980) Preparation of separate astroglial and oligodendroglial cell cultures from rat cerebral tissue. J. Cell Biol. 85: 890-902.

Nister, M., C. H. Heldin, A. Wateson, and B. Westermark (1984) A glioma-derived analog to platelet-derived growth factor: Demonstration of receptor competing activity and immunological cross activity. Proc. Natl. Acad. Sci. USA 81: 926-930.

Pfeiffer, S. E. (1977) Clonal lines of glial cells. In Tissue Culture of the Nervous System, G. Sato, ed., pp. 203-230, Plenum, New York.

Russell, D. S., and L. J. Rubenstein (1977) In Pathology of Tumors of the Nervous System, 4th Ed., Williams and Wilkins, Baltimore, MD.

Sundarraj, N., M. Schachner, and S. E. Pfeiffer (1975) Biochemically differentiated mouse glial lines carrying a nervous system specific cell surface antigen (NS-1). Proc. Natl. Acad. Sci. USA 72: 1927-1931.

Todaro, G., and L. A. Greene (1963) Quantitative studies of the growth of mouse embryo cells in culture and their development into established lines. J. Cell Biol. 17: 299-313.

Westermark, B. (1973) The deficient density-dependent growth of human malignant glioma cells and virus-transformed glia-like cells in culture. Int. J. Cancer 12:438-451.

Westermark, B., M. Nester, and C. H. Heldin 1985) Growth factors and oncogenes in human malignant glioma. Neurol. Clin. 4: 785799.

Whittenberger, B., and L. Glaser (1977) Inhibition of DNA synthesis in cultures of $3 \mathrm{~T} 3$ cells by isolated surface membranes. Proc. Natl Acad. Sci. USA 74: 2252-2255.

Whittenberger, B., D. Ruben, M. A. Lieberman, and L. Glaser (1978) Inhibition of growth of $3 \mathrm{~T} 3$ cells by extract of surface membranes. Proc. Natl. Acad. Sci. USA 75: 5457-5461. 